\title{
Beyşehir (Konya) ilç̧esi Elma Bahçelerinde Elma İçkurdu [Cydia pomonella (L.) (Lep.: Tortricidae)]'nun Ergin Popülasyon Gelişimi ve Bulaşıklık Oranlarının Belirlenmesi
}

\author{
Hasan ÇELIKK ${ }^{1}$, Levent ÜNLÜ2* \\ ${ }^{1}$ Gıda Tarım ve Hayvancılık illçe Müdürlüğü, Derebucak/Konya \\ [ORCID ID: http://orcid.org/0000-0001-6695-2061] \\ ${ }^{2}$ Selçuk Üniversitesi Ziraat Fakültesi Bitki Koruma Bölümü, Selçuklu/Konya \\ [ORCID ID: http://orcid.org/0000-0002-3142-3756] \\ *Sorumlu yazar: ulevent@selcuk.edu.tr
}

Öz

Bu çalışma, Beyşehir (Konya) ilçesinde 2014 ve 2015 yıllarında Genek ve Soğla lokasyonlarında seçilen üç adet elma bahçesinde yürütülmüştür. Çalışma ile Beyşehir Merkez'de Elma İçkurdu [(Cydia pomonella (L.) (Lep.: Tortricidae)]'nun ergin popülasyon gelişimi, ilk ergin çıkış tarihi, zararlı popülasyonunun oluşturduğu tepe noktaları, erginlerin doğada aktif olarak bulunduğu süre ve bulaşıklık oranları tespit edilmiştir. Elma içkurdunun ergin popülasyon gelişiminin takibi için eşey feromon tuzakları kullanılmıştır. Genek mevkiinde seçilen bir bahçede iki adet, Soğla mevkiinde belirlenen iki bahçede ise sırasıyla dört ve iki adet tuzak kurulmuştur. Zararlının sebep olduğu bulaşıklık oranını tespit etmek için meyvelerde ceviz büyüklüğü döneminden itibaren haftalık olarak örneklemeler yapılmıştır. Çalışma sonucunda, her iki lokasyonda da eşeysel çekici tuzaklarla belirlenen ergin popülasyonu 2014 ve 2015 yıllarında sırasıyla iki ve üç kez tepe noktası oluşturmuştur. Beyşehir'de Elma içkurdunun yıllara ve iklim şartlarına göre 2-3 döl verdiği kaydedilmiştir. Mayıs ayının ilk haftasında gerçekleşen ilk ergin çıkışının ardından 5 ay süre ile bahçelerde görülen erginler, eylül ayının sonlarına kadar uçuşuna devam etmiştir. Bahçelerde 2014-2015 yıllarında yapılan gözlemler sonucunda ortalama bulaşıklık Genek'te sırasıyla \%14.4 ile \%3.1 oranında; Soğla'da ise yine sırasıyla \%1.3 ile \%1.1 oranında saptanmıştır.

Anahtar Kelimeler: Elma içkurdu, Eşeysel çekici tuzaklar, Popülasyon gelişimi, Bulaşıklık oranı, Elma

\section{Determination of Adult Population Development and Infestation Rates of Coldling Moth [Cydia pomonella (L.) (Lep.: Tortricidae)] in Apple Orchards in Beyşehir (Konya)}

\begin{abstract}
The present study was carried out in three different apple orchards located in Genek and Soğla near Beyşehir district (Konya) during the 2014 and 2015 growing seasons. With this study, adult population development of Codling moth [Cydia pomonella (L.) (Lep.: Tortricidae)], the first adult flight, the peaks of the pest population, the time period during which the adults were active in the nature and the infestation rates of the pest were determined in the center of Beyşehir. Sex pheromone traps were used to follow adult population development of Codling moth. In the selected orchard in Genek, two traps, but in two orchards in Soğla location two and four traps were used, respectively, during the study period. To determine infestation rates of the pest, weekly samplings were made in fruits from the time of walnut size. As a result of this study, the adult populations identified with sexual traps in both locations attained two and three peak points in 2014 and 2015, respectively. In Beyşehir, it was recorded that Codling moth had 2-3 generations according to the year and climatic conditions. After the first adult flight in the first week of May, adults were seen in the orchards for 5 months and continued to fly until the end of September. As a result of observations made in the orchards in 2014-2015, the average infestation rates were $14.4 \%$ to $3.1 \%$ in Genek and $1.3 \%$ to $1.1 \%$ in Soğla, respectively.
\end{abstract}

Key Words: Codling moth, Sex pheromone traps, Population development, Infestation rate, Apple 
Giriş

Elma, dünya üzerinde çok geniş alanlara yayılmış bir kültür bitkisidir. Elmanın anavatanı Anadolu'nun da içinde bulunduğu Güney Kafkaslar'dır. Ülkemizin hemen hemen her bölgesinde rahatlıkla yetişebilen bir meyve olan elmanın, dünyada 6500 kadar çeşidi bulunmaktadır. Ülkemizde yetiştiriciliği yapılan elma çeşidi ise 460 civarındadır. Ülkemizde en fazla Starking, Golden, Starkrimson ve Amasya çeşitleri yetiştirilmektedir (Oğuz ve Karaçayır, 2009).

Türkiye yıllık 2.5 milyon tonluk üretimi ile elma üretiminde dünya sıralamasında dördüncü sırada yer almaktadır. Verim açısından beşinci sırada yer alan ülkemizin, kişi başına elma tüketim oranı da dünya ortalamasından fazladır. Üretim miktarı yüksek oranlarda olmasına karşın, ürettiğimiz elmanın yalnızca \%0.3'ünü ihraç edebilmekteyiz (Oğuz ve Karaçayır, 2009).

Beyşehir, 243 ha alanda yaklaşık 80.000 elma ağacı ile 2760 ton üretim kapasitesine sahip bir ilçedir. Bu üretim miktarı ile Konya ili elma üretiminin $\% 7^{\prime}$ lik bir kısmını karşılamaktadır (Anonim, 2015a). Beyşehir ilçesinde göl etrafında bulunan arazilerde sulama imkânının olması, arazilerin ve iklim koşullarının elma yetiştiriciliğine uygun olması nedeniyle, elma üretimi açısından önemli bir potansiyele sahiptir.

Beyşehir ilçesinde de diğer bölgelerde olduğu gibi üretim aşamasında ortaya çıkan bazı hastalık ve zararlılar elma verimi üzerine etkili olmaktadır. Elma yetiştiriciliğinin ana zararlısı olarak Elma içkurdu [Cydia pomonella (L.) (Lep.: Tortricidae)] önemli bir yer tutmaktadır. Ülkemizde elma üretim bölgelerinin her yerinde bulunan Elma içkurdu, genellikle iki döl, bazı yer ve yıllarda üç döl verebilmektedir. Başta elma olmak üzere armut, ayva ve cevizde zararlı olmakta; bunların yanı sıra erik, kayısı ve şeftalide az oranda bulunabilmektedir (Anonim, 2008).

Beyşehirli üreticiler zararlı ile mücadelede, kimyasal mücadeleyi uygulama kolaylığı ve çabuk sonuç alma gibi nedenlerden dolayı diğer çiftçiler gibi tercih etmektedirler. Bilinçsiz ve zamansız yapılan insektisit kullanımı çevreye ve doğal düşmanlara zarar vermektedir. Son yıllarda dünyada ve ülkemizde biyoteknik mücadele yöntemleri ile ilgili araştırmalar artmaktadır. Biyoteknik mücadele yöntemlerinden birisi de eşeysel çekici feromon tuzaklarıdır. Bu tuzaklar dünyada ve Türkiye'de pek çok zararlıya karşı uygulanmaktadır.

Eşeysel çekici feromon tuzakları aynı zamanda pek çok çalışmada popülasyonun durumunun belirlenmesi noktasında kullanılmaktadır. Elma içkurdu üzerine yapılan; popülasyon gelişimi, feromonlar tuzaklarda çekici olarak kullanılan maddelerin etkinliği, mücadelede uygun zaman ve değişik etken maddeli kimyasal ilaçların etkinliğinin belirlenmesi gibi çalışmalarda bahçelere asılan feromon tuzaklar ile popülasyondaki değişimler takip edilmektedir (Önder, 1987; Layık ve Kısmalı, 1994; Hepdurgun ve ark., 1996; Kılıç ve ark., 1999; Kutinkova ve ark., 2009; Knight, 2010; Kakar ve ark., 2015).

Elma içkurdunun popülasyon gelişiminin belirlenmesinde eşeysel çekici tuzaklar yaygın olarak kullanılmaktadır. Bu tuzaklar bahçedeki her yüz ağaca bir adet olacak şekilde yerden 1.5-2 m yüksekliğe asılır. Tuzaklar haftada bir kez kontrol edilerek yapışkan tabla üzerine yapışan erginlerin sayılmasıyla ilaçlama zamanı hakkında bilgi edinilmiş olunur (Anonim, 2011).

Ege Bölgesi'nde Elma içkurdunun feromon tuzakları ile kitlesel tuzaklama yöntemini kullanarak bu yöntemin tek başına olmasa bile diğer mücadele yöntemleri ile entegre bir şekilde kullanılabileceği bildirilmiştir 
(Hepdurgun ve ark., 1996). Yine Önder (1987), Ege Bölgesi'nde Elma içkurduna karşı kimyasal savaşımda tahmin ve uyarıya esas olarak eşeysel çekici tuzaklarla, etkili sıcaklık toplamlarından yararlanma olanaklarını araştırmıştır. Kılıç ve ark. (1999), Karadeniz'de, Elma içkurdunun feromon tuzakları ile popülasyon gelişimi ve bulaşıklık oranlarını saptamışlardır.

Mamay ve Yanık (2013), zararlının Şanlıurfa ilindeki popülasyon gelişimini ve bulaşıklık oranı hakkında bilgi vermişlerdir. Dindar ve Ecevit (1996), zararlının cevizlerde de zarar yaptığını bildirmiştir. İşçi (2008), Elma içkurdunun farklı zamanda yetişen elma çeşitlerinde farklı oranda zarar yaptığını kaydetmiştir. Bayraktar (2015), zararlının mücadelesinde kullanılmak üzere Karaman ilinde bazı ekolojik bilgileri saptamıştır.

Bu çalışmayla, Beyşehir illçesi için ekonomik getirisi olan elma bahçelerindeki en önemli zararlı konumundaki Elma içkurdunun, popülasyon gelişimi ve meyvelerdeki bulaşıklık oranının belirlenmesi amaçlanmıştır. Bu sayede tuzaklardaki ergin yoğunluğu dikkate alınarak belirlenen mücadele zamanlarında yapılan doğru müdahaleler ile üreticilerin aşırı ilaç kullanımının önüne geçilmesi amaçlanmıştır.

\section{Materyal ve Metot}

Çalışmanın ana materyalini Beyşehir ilçesinde yetiştirilen elma ağaçları ile bu ağaçlar üzerinde zarar yapan Elma içkurdu oluşturmuştur. Elma içkurdu popülasyon gelişimini belirlemek için ise delta tipi eşeysel çekici feromon tuzakları (1.5 mg E.E-8.10dodecadien-1-ol) kullanılmıştır. Çalışmada bahçe koordinatları GPS cihazı ile belirlenmiştir. Çalışmanın yapıldığı Beyşehir'de bahçelere ait bilgiler Çizelge 1'de verilmiştir.

Çizelge 1. Elma içkurdunun ergin popülasyon gelişimi ve bulaşıklık oranlarının belirlendiği elma bahçeleri

Table 1. Apple orchards where adult population development and infestation rates of Codling moth were determined

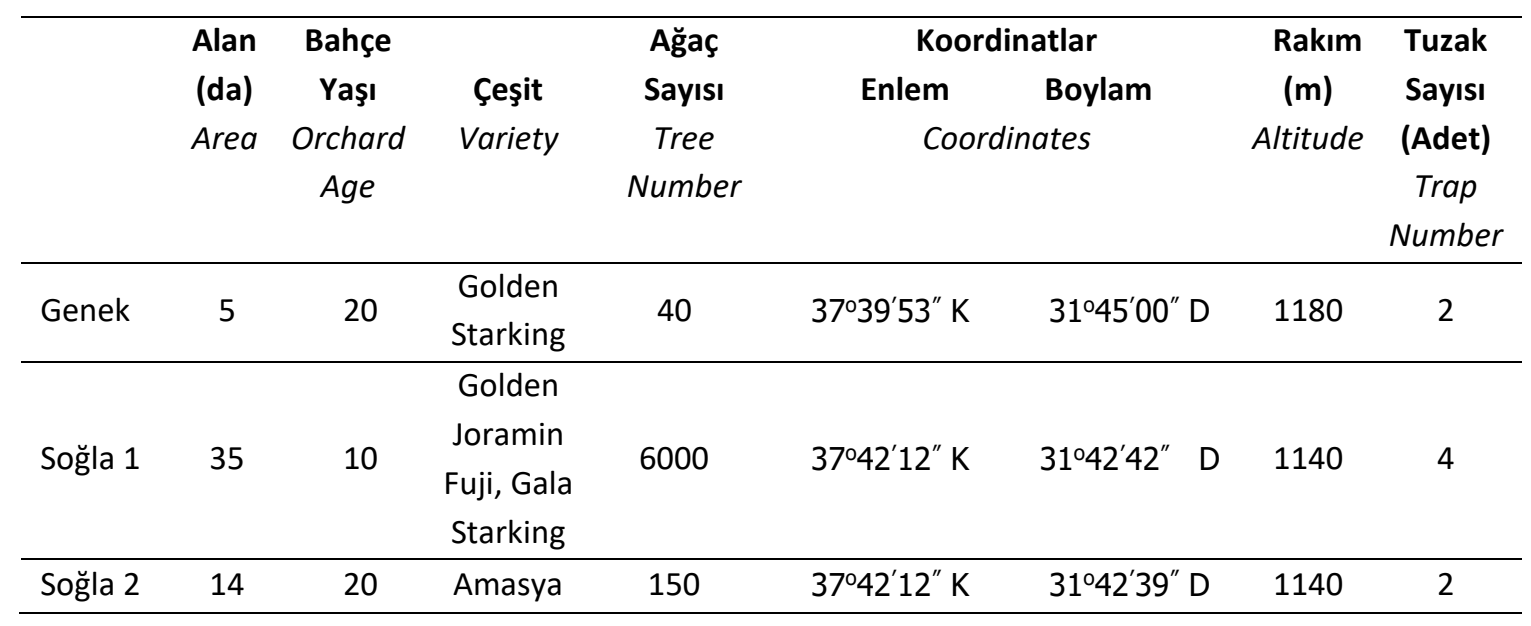

Elma içkurdunun Popülasyon Gelişiminin Belirlenmesi

Eşeysel çekici feromon tuzakları elma bahçelerine mayıs ayının ilk haftası içerisinde yerden yaklaşık $1.5 \mathrm{~m}$ yüksekliğe asılmıştır. Ergin bireyler tuzaklarda görülünceye kadar her gün, erginler görüldükten sonra ise haftada bir kez kontrol edilerek yakalanan 
ergin sayıları kaydedilmiştir. Tuzaklarda yakalanan erginler yapışkan kısımdan her kontrolde temizlenmiştir. Feromon kapsüller beş haftada bir değiştirilmiştir. Yapışkan tablalar ise yapışkan özelliği dikkate alınarak gerek görüldüğünde değiştirilmiştir.

\section{Elma içkurdunun Bulaşıklık Oranının Belirlenmesi}

Elma içkurdu bulaşıklık oranını belirlemek için, örnekleme yapılan elma bahçelerinde bulaşık meyveler görüldüğü andan itibaren kontrollere başlanmıştır. Çalışmanın yürütüldügü bütün bahçelerde bulaşıklık, her hafta bahçeyi temsil edecek şekilde rastgele seçilen elma ağaçlarından toplam 100 adet meyve incelenmiştir. Geleneksel şekilde yetiştiricilik yapılan Genek ve Soğla 2'de rastgele belirlenen 5 ağaçta 20 meyve incelenmiştir. Soğla $1^{\prime}$ de ise rastgele seçilen 10 ağaçta 10 adet meyve kontrol edilmiştir. Bulaşık meyve sayısı toplam meyve sayısına bölünerek bulaşıklık oranı hesaplanmıştır. Düzenli olarak her hafta sayılan bulaşık meyvelerin aritmetik ortalaması alınarak elma bahçelerindeki Elma İçkurdunun bulaşıklık oranı hesaplanmıştır.

\section{Araştırma Bulguları ve Tartışma}

\section{Elma İçkurdunun Ergin Popülasyon Gelişimi}

Zararlının popülasyon durumunu belirlemek amacıyla eşeysel çekici tuzaklar ortalama sıcaklığın $13{ }^{\circ} C^{\prime}$ ye ulaştığı mayıs ayının ilk haftasında üç farklı bahçede kurulmuştur. Zararlının Genek mevkiindeki 2014-2015 yıllarında ergin popülasyon gelişimi Şekil 1'de verilmiştir.

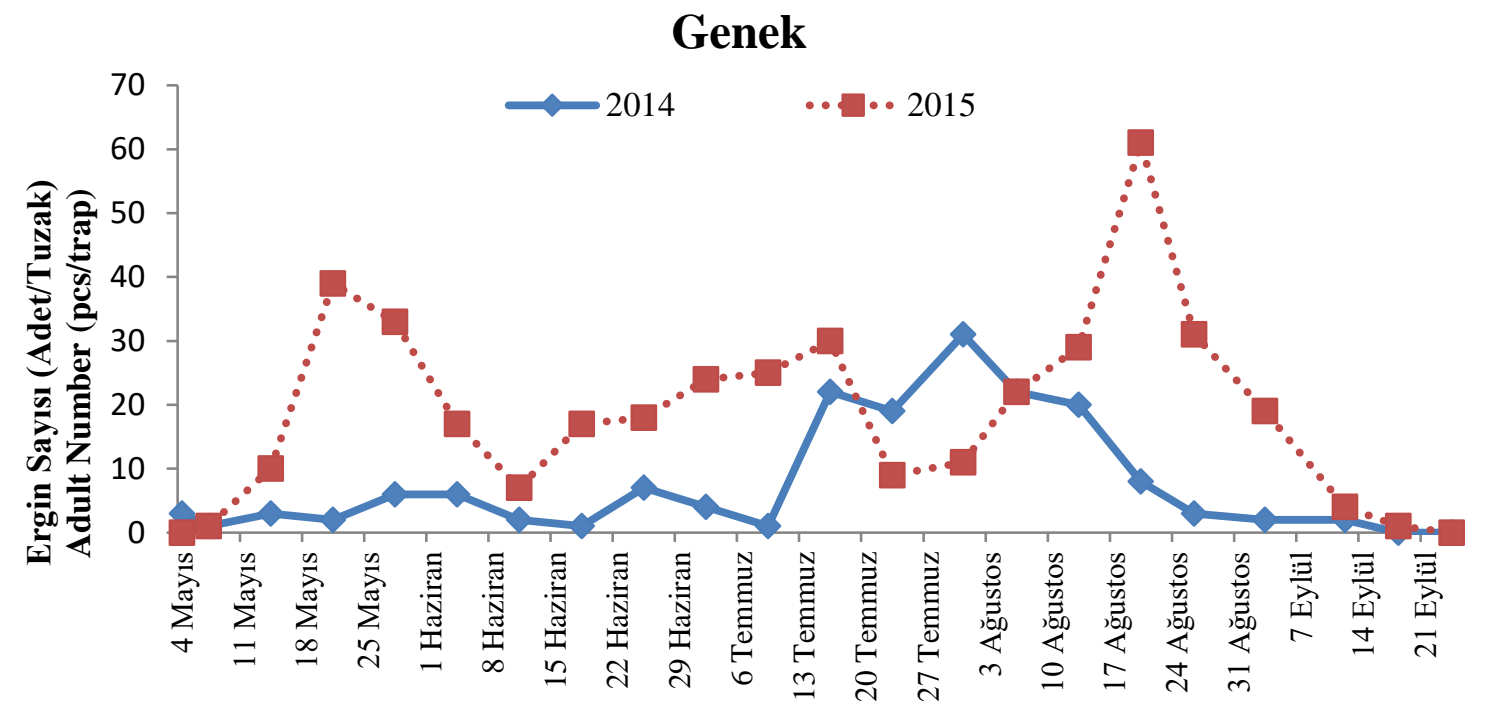

Şekil 1. Genek'de 2014-2015 yıllarında elma bahçesinde Cydia pomonella ergin popülasyon gelişimi.

Figure 1. Adult population development of Cydia pomonella in apple orchard at Genek in 20142015.

Genek'te 2014 yılında Elma içkurdu feromon tuzaklarında ilk kez 4 Mayıs tarihinde yakalanmıştır. Zararlı, 25 Haziran'da

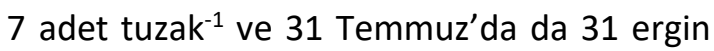

tuzak $^{-1}$ ile iki kez tepe noktası oluşturmuştur. Popülasyonun daha yoğun seyrettiği 2015 yılında zararlının ilk ergini 7 Mayıs'ta yakalanıp, 20 Mayıs'ta 39 ergin tuzak ${ }^{-1}, 15$ 
Temmuz'da 30 ergin tuzak ${ }^{-1}$ ve son olarak da 19 Ağustos'ta 61 ergin tuzak ${ }^{-1}$ ile üç kez tepe noktası oluşturmuştur (Şekil 1). Feromon tuzaklarında yakalanan toplam ergin sayısı 2014 yııına oranla 2015 yılında üç kat artış göstermiştir.

Genek'de Elma içkurdu popülasyonunun 2014 ve 2015 yılındaki gelişimi farklılık göstermektedir. Bu şekilde bir farklılı̆ın görünmesinde 2014 yılında Mayıs, Haziran, Eylül ve Ekim aylarının yağışlı geçmesine bağlanabilmektedir.

Genek'de kurulan eşeysel çekici feromon tuzaklarıyla ilk ergin çıkışının mayıs ayının ilk haftasına tekabül ettiği belirlenmiştir. Erginlerin tuzaklarla yakalandığı son tarih ise 16 Eylül olarak tespit edilmiştir. Beyşehir Genek mevkiinde C. pomonella erginlerinin 2014-2015 yıllarında elde edilen verilere göre doğada 4.5 ay süreyle aktif olduğu belirlenmiştir (Şekil 1). Elma içkurdu popülasyonu 2015 yılında 13 Mayıs-3 Haziran, 16 Haziran-15 Temmuz ve 30 Temmuz-26 Ağustos tarihleri arasında yapılacak 4-5 kimyasal ilaç kullanımı ile beraber alınacak kültürel önlemler ile mücadelede başarı sağlanabileceği tespit edilmiştir.

Cydia pomonella'nın Soğla 1'de 2014-2015 yılları arasında gerçekleşen popülasyon gelişimi Şekil 2'de verilmiştir. Soğla 1'de 2014 yılında C. pomonella erginleri 4 Mayıs'ta yakalanmıştır. Yıl boyunca düşük bir popülasyon seyri sergileyen zararlı, 16 Temmuz'da 3 adet tuzak-1 ve 20 Ağustos'ta 14 ergin tuzak $^{-1}$ ile iki kez tepe noktası oluşturmuştur (Şekil 2). Popülasyon yoğunluğundaki bu düşüklüğün nedeni; üreticinin erken uyarı sistemleri ile $C$. pomonella için mücadele zamanlarını duyuran resmi kurumların uyarılarını dikkate alarak mücadele yapmasının etkili olduğu düşünülmektedir. Aynı zamanda toplu elma bahçelerinde Elma içkurdunun hareketliliğinin düşük olduğunu belirten çalışmalar da mevcuttur (Howell ve ark., 1992). Diğer parsellere göre daha büyük olan Soğla 1'de bahçenin iç kısımlarında Elma içkurdunun etkisinin daha düşük olduğu belirlenmiştir.

Çalışmanın yürütüldüğü her iki yılda da feromon tuzaklarında ilk ergin çıkışı mayıs ayının ilk haftasında kaydedilen Soğla 1'de son ergin eylül ayının ilk günlerinde görülmüştür. Soğla 1'de erginlerin aktif olarak bulunduğu süre 4.5 ay olarak tespit edilmiştir (Şekil 2).

Soğla 1'de 2015 yılında bir önceki yıla nazaran yağışların daha az olması ve sıcaklıkların bir iki derece yüksek olması $C$. pomonella popülasyonunda artışa neden

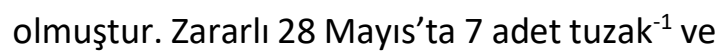

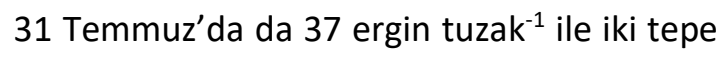
noktasına ulaşmışı ır (Şekil 2). 


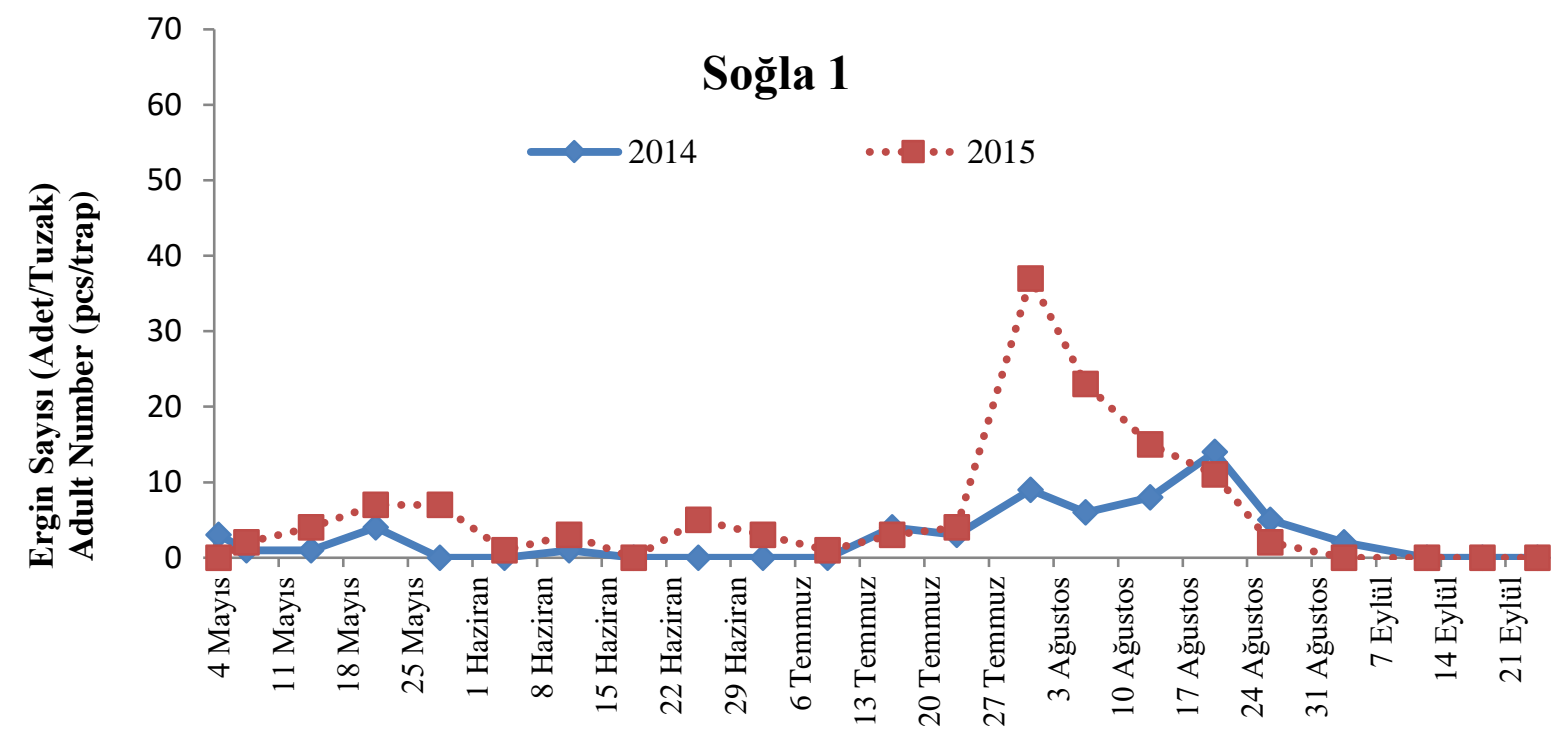

Şekil 2. Soğla 1'de 2014-2015 yıllarında elma bahçesinde Cydia pomonella ergin popülasyon gelişimi.

Figure 2. Adult population development of Cydia pomonella in apple orchard at Soğla 1 in 20142015.

Cydia pomonella'nın aynı mevkide gerçekleşen popülasyon gelişimi Şekil 3'te bulunan Soğla 2'de de çalışmalar yapılmıştır. verilmiştir.

Bu mevkide 2014-2015 yılları arasında

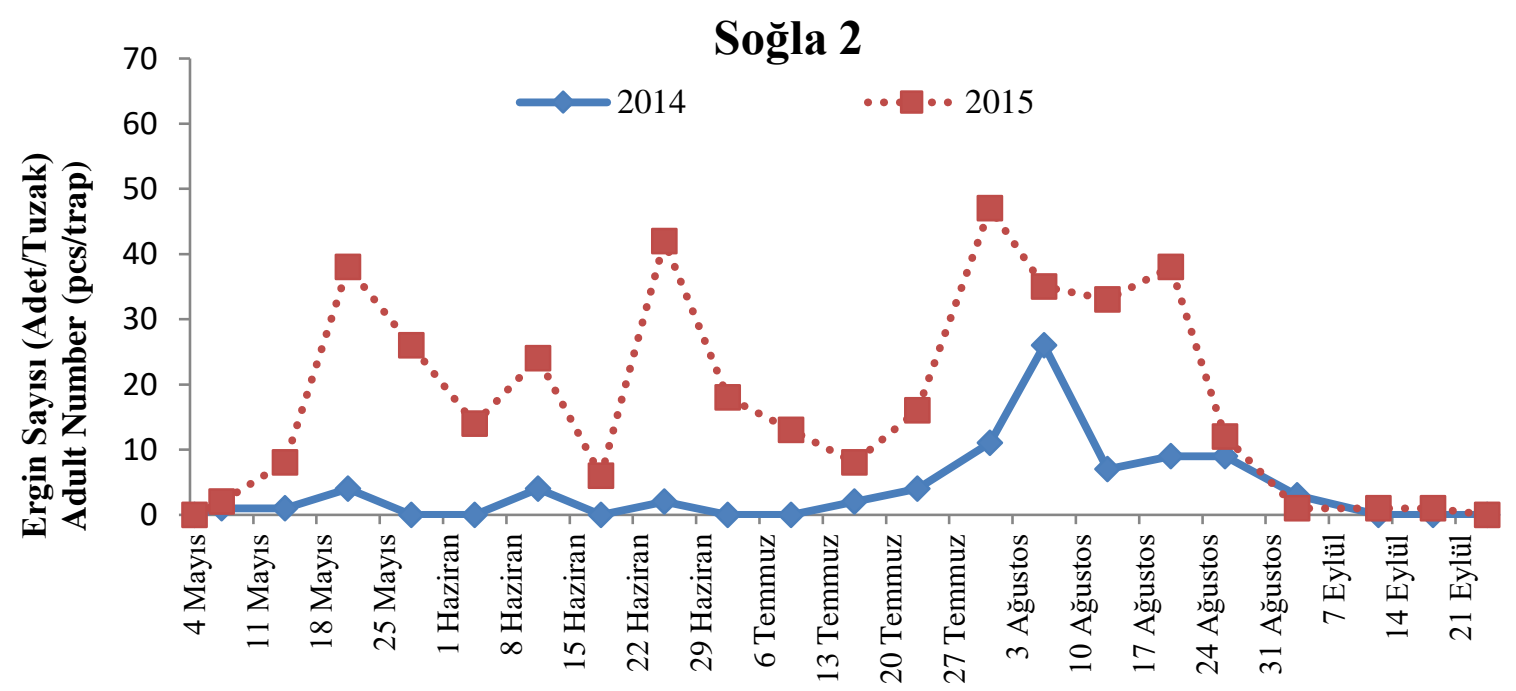

Şekil 3. Soğla 2'de 2014-2015 yıllarında elma bahçesinde Cydia pomonella ergin popülasyon gelişimi.

Figure 3. Adult population development of Cydia pomonella in apple orchard at Soğla 2 in 20142015. 
Soğla 2'de 2014 yılında ilk C. pomonella erginleri 7 Mayıs'ta yakalanmıştır. Yıl boyunca düşük bir popülasyon seyri sergileyen zararlı, 11 Haziran'da 4 adet tuzak ${ }^{-1}$ ve 6 Ağustos'ta

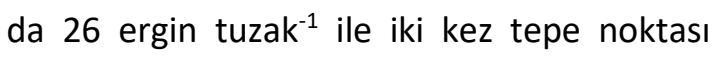
oluşturmuştur (Şekil 2). Elma içkurdu, 2015 yılında 21 Mayıs'ta 38 ergin tuzak $^{-1}, 25$ Haziran'da 42 ergin tuzak ${ }^{-1}$ ve son olarak 31 Temmuz'da da 47 ergin/tuzak ile üç kez tepe noktası oluşturmuştur (Şekil 3). ilk yıla oranla eşeysel çekici feromon tuzaklarında yakalanan ergin sayısı yaklaşık dört kat artış göstermiştir. Bu artışı, 2014 yılı mayıs ve haziran aylarının yağışlı geçmesi nedeniyle özellikle birinci döl çıkışarının az olmasına bağlayabiliriz. Çünkü, 2015 yılında hava şartlarındaki uygunluk nedeniyle mayıs ve haziranda birinci döl ergin popülasyonunun bir önceki yıla göre önemli ölçüde artış göstermiştir (Şekil 3).

Soğla 2'de mayıs ayının ilk haftasında tuzaklarda yakalanan erginler, eylül ayının sonuna kadar diğer bahçelerde olduğu gibi yaklaşık 4.5 ay süreyle aktif olduğu belirlenmiştir (Şekil 3). Çanakkale'de yapılan araştırmada C. pomonella ergin çıkışı nisan ayının başında başlamış ve eylül ayı sonlarına kadar devam ettiği belirlenmiştir (Özpınar ve ark., 2009). Şanlıurfa'da ise C. pomonella erginlerinin nisan ayının sonundan eylül ayının sonuna kadar yaklaşık beş ay aktif oldukları sonucuna ulaşılmıştır (Mamay ve Yanık, 2013).

Aynı bölgede olmasına rağmen 2015 yılı ergin popülasyonunda yükseliş görülmekle birlikte özellikle ilk döl çıkışlarında Soğla 1'de önemli bir değişiklik görülmemiştir. Soğla 2' de hem yoğunluk hem de oluşturduğu üç tepe noktası nedeniyle önemli bir fark ortaya çıkmışır. Bu farkın Soğla 2'de yapılan geleneksel yetiştiricilikten kaynaklandığı söylenebilir. Geleneksel şekilde yetiştirilen Amasya çeşidi elma ağaçlarının gövde kabukları arasındaki çatlaklarda uygun pupa ortamının oluşması ve meyve ağaçlarındaki taç genişliği nedeniyle homojen şekilde ilaçlamanın yapılamaması gibi sebeplerin popülasyon yoğunluğu üzerinde etkisi olduğu gözlemlenmiştir.

Elma içkurdu Beyşehir merkezde tüm bahçelerde iklim şartlarına bağlı olarak 20142015 yıllarında sırasıyla 2-3 kez tepe noktası oluşturmuştur. Ülkemizde Elma içkurdu genellikle iki döl, bazı yer ve yıllarda üç döl verebilmektedir (Anonim, 2008). Ülkemizin değişik bölgelerinde yapılan popülasyon gelişimi çalışmaların da olduğu gibi bizim elde ettiğimiz veriler de bu bilgiyi doğrulamaktadır (Özpınar ve ark., 2009; Şahin, 2010; Mamay ve Yanık, 2013).

Elma içkurdu popülasyonunu belirlemek için kurulan eşeysel çekici tuzaklarda 2014 yılında Genek (165 ergin), Soğla 1 (61 ergin) ve Soğla 2 (83 ergin)'de toplam 309 ergin yakalanmıştır. Çalışmanın ikinci yılında Genek (408 ergin), Soğla 1'de (129 ergin) ve Soğla 2'de (384 ergin) olmak üzere toplamda 921 ergin yakalanmıştır. Tuzaklarla yakalanan ergin sayıları dikkate alındığında C. pomonella popülasyonu 2015 yılında yaklaşık üç kat artmıştır.

Pakistan'nın Dheerkot bölgesinde popülasyon gelişimi ile ilgili yapılan bir çalışmada cinsel çekici feromon tuzaklarında toplamda 2000 yılında 282 adet, 2001 yılında ise 199 adet ergin yakalandığı belirtilmiştir (Ahmad ve ark., 2003). Ülkemizde ise, Şanlıurfa'da yapılan araştırmada tuzaklarda yakalanan ergin sayısının 2010 yılında 550 adet, 2011 yılında 400 adet olduğu belirtilmiştir (Mamay ve Yanık, 2013). Yapılan her iki çalışmada da bahçelere birer adet eşeysel çekici feromon tuzak kurulmuştur.

Beyşehir ilçesinde bulunan 1140-1180 m rakımlı elma bahçelerinde toplamda sekiz adet eşeysel çekici feromon tuzak kullanılarak 
yapılan bu çalışmada, ilkbahar aylarının yağışlı geçtiği 2014 yılında toplamda yakalanan 309 ergin (38.6 ergin tuzak ${ }^{-1}$ ) ile düşük bir popülasyon yoğunluğu gözlemlenmiştir. 2015 yılında tuzaklarda yakalanan ergin sayısı toplamda 921 ergin (115 ergin tuzak ${ }^{-1}$ ) olarak gerçekleşmiştir. Beyşehir'de elde edilen bu popülasyon yoğunluğunun benzer çalışmalara göre düşük olduğu göze çarpmaktadır.

Beyşehir'de 2015 yılı verileri dikkate alınarak 20 Mayıs-10 Haziran, 24 Haziran-15 Temmuz ve 29 Temmuz-2 Eylül tarihleri popülasyonun yoğunluğunun yükseldiği tarihleri ifade etmektedir. Beyşehir'de bu tarihler arasında yapılacak mücadelenin sonuç alma bakımından önemi çok fazladır. Üreticilerin 9-13 kez ilaç attıkları Elma içkurduna karşı, eşeysel çekici feromon tuzaklarıyla belirlenen bu tarihlerde 4-5 kez yapılacak kimyasal mücadelenin Beyşehir'de Elma içkurdu mücadelesinde etkili olduğu belirlenmiştir.

Pakistan'da Elma içkurdunun popülasyon gelişimini izlemek için gün derece hesaplaması ve feromon tuzaklar kullanılmıştır (Kakar ve ark., 2015). Çalışma sonucunda larva kontrolü için feromon tuzakları ve gün derece esası ile kombine olarak yılda 3-4 ilaçlamanın gerekliliği vurgulanmıştır. Nitekim, Çanakkale ilinde mücadelede zararlının yoğunluğunun dikkate alınmasının gerekliliği belirtilmiştir. Bu sayede mücadelede kimyasal ilaç kullanımının azaltılarak entegre mücadele programına destek verilmesinin mümkün olabileceği ifade edilmektedir (Şahin, 2010). Isparta ilinde çiftleşmeyi engelleme ile kimyasal mücadele yöntemlerinin etkinliği araştırılarak, organik yetiştiricilik yapan üreticilerin çiftleşmeyi engelleme yöntemini tek başına kullanılabilecekleri, popülasyonun yüksek olduğu yerlerde çiftleşmeyi engelleme yönteminin, insektisitlerle kombine edilerek uygulanmasının daha iyi sonuç verebileceği belirtilmiştir (İş̧̧i ve ark., 2011).

Elma içkurdunun Bulaşıklık Oranının Belirlenmesi

Popülasyon gelişiminin belirlenmesinin yanı sıra bulaşıklık oranının belirlenmesi de Elma içkurdunun bahçelerde oluşturduğu zararın tespiti açısından önemlidir. Bahçelerde görülen bulaşıklık miktarı esas olarak Elma içkurdunun üreticiye neden olduğu maddi kaybı ifade eder. Mücadele edilmediği zaman elma bahçelerinde büyük zararlara yol açan C. pomonella'nın, çalışmanın yürütüldüğü 2014 yılında meyvelerde neden olduğu bulaşıklık oranı Çizelge 2'de verilmiştir.

Çizelge 2. Beyşehir'de 2014 yılında elma bahçelerinde Cydia pomonella bulaşıklık oranı (\%).

Table 2. Infestation rates of Cydia pomonella in apple orchards in Beysehir in 2014 (\%).

\begin{tabular}{cccc}
\hline Tarih Date & Genek & Soğla 1 & Soğla 2 \\
\hline 23.07 .2014 & 0.0 & 0.0 & 0.0 \\
31.07 .2014 & 0.0 & 0.0 & 0.0 \\
06.08 .2014 & 0.0 & 0.0 & 1.0 \\
13.08 .2014 & 7.0 & 0.0 & 2.0 \\
20.08 .2014 & 7.0 & 0.0 & 4.0 \\
26.08 .2014 & 24.0 & 1.0 & 0.0 \\
03.09 .2014 & 26.0 & 0.0 & 0.0 \\
12.09 .2014 & 27.0 & 6.0 & 0.0 \\
18.09 .2014 & 27.0 & 4.0 & 1.0 \\
24.09 .2014 & 26.0 & 3.0 & 4.0 \\
\hline Ortalama Bulaşıklık & $\mathbf{1 4 . 4}$ & $\mathbf{1 . 4}$ & $\mathbf{1 . 2}$ \\
Average Infestation & & & \\
\hline
\end{tabular}


Genek'de 2014 yılında C. pomonella'nın meyvelerde oluşturduğu bulaşıklıık, ağustos ayında \%7 seviyelerinde iken, giderek yükselmiş eylül sonu itibariyle \%26'lara kadar yükseldiği gözlemlenmiştir. Meyvelerde, 2014 yılı genelinde görülen bulaşıklığın ortalama \%14.4 olduğu belirlenmiştir (Çizelge 2).

Soğla 1'de C. pomonella'nın bulaşıklık oranı üretim sezonu boyunca yapılan haftalık kontrollerde en yüksek \%6 seviyesine ulaşmıştır. Popülasyon yoğunluğunun diğer bahçelere göre düşük seyrettiği Soğla 1'de 2014 yılı genelinde bulaşıklılık \%1.4 olarak tespit edilmiştir.

Soğla 2'de 2014 yılı genelinde bulaşıkııık \%1.2 olarak gerçekleşmiştir (Çizelge 2). Bahçede görülen popülasyon yoğunluğuna oranla meyvelerde görülen bulaşıklılık miktarları son derece düşüktür. Zararlının 2015 yılındaki bulaşıklılık oranı Çizelge 3'te verilmiştir.

Çizelge 3. Beyşehir'de elma bahçelerinde 2015 yıllında Cydia pomonella bulaşıklılık oranları (\%). Table 3. Infestation rates of Cydia pomonella in apple orchards in Beyşehir in 2015 (\%).

\begin{tabular}{cccc}
\hline $\begin{array}{c}\text { Tarih } \\
\text { Date }\end{array}$ & Genek & Soğla 1 & Soğla 2 \\
\hline 05.08 .2015 & 0.0 & 0.0 & 0.0 \\
11.08 .2015 & 0.0 & 1.0 & 0.0 \\
19.08 .2015 & 4.0 & 0.0 & 3.0 \\
26.08 .2015 & 5.0 & 0.0 & 2.0 \\
02.09 .2015 & 6.0 & 0.0 & 1.0 \\
09.09 .2015 & 2.0 & 0.0 & 2.0 \\
16.09 .2015 & 2.0 & 4.0 & 1.0 \\
21.09 .2015 & 2.0 & 4.0 & 0.0 \\
29.09 .2015 & 3.0 & 2.0 & 0.0 \\
07.10 .2015 & 7.0 & 2.0 & 0.0 \\
\hline Ortalama Bulaşıklık & $\mathbf{3 . 1}$ & $\mathbf{1 . 3}$ & $\mathbf{0 . 9}$ \\
Average Infestation & & & \\
\hline
\end{tabular}

Genek'de 2015 yılında haftalık yapılan kontrollerde bulaşıklılık oranı yıl boyu \%2-7 arasında değişerek bir önceki yıla göre önemli bir artış göstermemiştir. Bulaşıklıık oranının düşük seyrettiği 2015 yılında Genek'te bulaşıklılık ortalama \%3.1 olarak tespit edilmiştir.

Çalışmanın yürütüldüğü Soğla mevkiindeki bahçelerde bulaşıklılık açısından bir önceki yıla göre önemli bir değişiklik olmamış, bulaşıklılık \%1-4 seviyesinde seyretmiştir. Genek mevkiinde ise 2014 yılında ortalama \%14.4 olan bulaşıklııı oranını 2015 yılında \%3.1 seviyesine düştüğü görülmüştür (Çizelge 3). C. pomonella popülasyonunun 2015 yılında daha yoğun seyretmesine rağmen bulaşıkılık oranında azalma görülmüştür.

Beyşehir illçe Gıda, Tarım ve Hayvancılık Müdürlüğü verilerine göre bulaşıklılık 20142015 yıllarında \%2 olarak tespit edilmiştir. Çalışmamız ile karşılaştırıldığında elma bahçelerinde 2014 yılında Genek'te tespit edilen \%14.4 bulaşıklık değeri haricindeki diğer bulgularla arasında farklılık görülmemiştir.

Ayrıca C. pomonella'nın çalışmada belirlenen popülasyon yoğunluğu ve bulaşıklılık oranlarına bakılarak özellikle ağustos ayı sonlarında çıkış yapan ikinci dölün bulaşıklılık üzerinde daha çok etkisi olduğu tespit edilmiştir. 
Genek'de 2014 yılındaki düşük popülasyon yoğunluğuna rağmen görülen \%14.4 düzeyindeki bulaşıklııı oranı, popülasyon yoğunluğunun 3 kat arttığı 2015 yılında \%3.1 olarak belirlenmiştir. Diğer elma bahçelerinde ise bulaşıklılık her iki yılda da \%0.9-1.4 seviyesinde kalmıştır. Bulaşıklılık oranındaki bu azalma, Elma içkurdu popülasyonunun gelişiminin takip edilerek doğru zamanlarda yapılan kimyasal mücadeleye bağlanabilir.

Sinop ilinde yapılan bir araştırmada Elma içkurdunun cevizlerde \%18-54 arasında zarara neden olduğu belirtilmiştir (Dindar ve Ecevit, 1996). Karaman'da bahçelerde meyvelerdeki zarar oranı \%80 dolaylarında iken 2012 yılında yapılan benzer bir çalışma ile meyvelerdeki bulaşıklı̆ın \%2 seviyesine indirildiği belirtilmiştir (Bayraktar, 2015).

Soğla 2'de 2014 yılında yapılan dört kimyasal ilaçlamada, ilaçlamaların meyvelerde oluşan bulaşıklılık oranını önemli derecede düşürdüğü görülmüştür.

Genek mevkiinde çalışmanın ikinci yılında bulaşıklılı̆ın bu derece azalması; ilk yıl $C$. pomonella ile mücadelede popülasyonun gelişiminin dikkate alınmaması gösterilebilir. Çünkü ikinci yıl kimyasal mücadelenin popülasyonun yoğun olduğu zamanlarda yapılması ile Genek'te 2015 yılında C. pomonella bulaşıklılık oranı \%3.1' e kadar düşmüştür. Genek'deki bahçede, 2014 yılında 20-25 gün arayla rastgele yapılan mücadelenin, bir sonraki yıl eşeysel çekici feromon tuzaklarla belirlenen popülasyon yoğunluğu dikkate alınarak yapılması ile açıklanabilir. Genek'de kimyasal mücadelenin 2015 verileri dikkate alınarak C. pomonella popülasyon yoğunluğunun önemli derecede arttığı 20 Mayıs-3 Haziran, 24 Haziran-15 Temmuz ve 5 Ağustos-2 Eylül tarihleri arasında yapılması zararlıya karşı başarı şansını oldukça artıracaktır.
Zararlının popülasyonunun yoğun seyrettiği yıllarda 6 ilaçlama, popülasyonun düşük olduğu yıllarda ise yapılan 4 ilaçlamanın mücadelede yeterli olduğu belirlenmiştir. Elma üreticilerinin rastgele yaptığı yılda 10 ilaçlamayı bulan aşırı kimyasal kullanımı ile aynı etkin sonuç alınamamaktadır. Zararının popülasyonunda görülen değişikliklere göre yapılan zamanında ilaçlama ekonomik olarak üreticilerin üzerinden önemli bir yükü kaldırmasının yanında zararlı ile mücadelenin başarılı olmasına sebep olur. Bu nedenle üreticilerin resmi kurumların yaptığı Elma içkurdu ilaçlama zamanı duyurularını dikkate alarak ilaçlama yapması önem arz etmektedir.

Çalışmada dikkat çeken noktalardan birisi de bahçe kenarlarındaki ağaçlarda bulaşıklığın, bahçenin ortalarında bulunan ağaçlara göre daha yoğun olmasıdır. Bunun nedeninin ise çiftleştikten sonra yumurta bırakacak olan dişilerin bahçeye dışarıdan geldiklerinde ilk buldukları elma ağaçlarına yöneldiği ve yol kenarındaki ilk sıra elma ağaçlarına daha çok yumurta bıraktıkları tahmin edilmektedir. Soğla 1'de popülasyonda görülen düşüklüğün dört metre arayla 31 sıra elma ağacı olması ve her sıranın uzunluğunun 100 m'yi geçmesi nedeniyle bahçe ortasında kalan bitkilerin Elma içkurdu ile daha az karşılaşmasının etkili olduğu düşünülmektedir. Kimyasal mücadele esnasında bahçeyi çevreleyen ağaçların ilaçla temasını artırıcı önlemler alınarak ilaçlamanın tesirinin arttırılması gerekir.

$\mathrm{Bu}$ durumla alakalı İtalya'nın Molise bölgesinde yapılan bir araştırmada Elma içkurdunun konukçu bitki şeritleri ile çevrilmiş elma bahçelerinde düşük hareketlilik gösterdiği tespit edilmiştir. Elma bahçeleri etrafında yapılacak en az $100 \mathrm{~m}$ genişliğindeki bitki şeritlerinin bulaşık bölgelerden gelen göçlere karşı bariyer etkisi olduğu belirtilmektedir (Trematerra ve ark., 2004). 
Eşeysel çekici feromonlar kullanılarak çiftleşmenin bozulma etkinliğini ölçmek için yapılan çalışmada elde edilen mekânsal analiz sonucu toplu meyve bahçelerinde Elma içkurdunun hareketinin sınırlı olduğu belirtilmiştir (Howell ve ark., 1992). Çalışmalardan elde edilen bu veriler, bahçeler etrafında değişik elma çeşitlerinden konukçu bitki şeritlerinin mümkün olduğu ölçüde uygulamasının gerekliliğini ortaya koymaktadır.

\section{Sonuçlar}

Çalışmada Elma içkurdu erginlerinin Beyşehir'de mayıs ayının ilk haftasında çıkış yaptıkları belirlenmiştir. Mayısın ilk haftasında başlayan Elma içkurdu popülasyonu hava şartlarının olumlu olduğu yılda üç tepe noktası, hava şartlarının olumsuz olduğu yılda ise ilki düşük sayıda olmak üzere, iki tepe noktası oluşturmuştur. Beyşehir'de Elma içkurdunun yıllara ve iklim koşullarına göre, yılda 2-3 döl verdiği tespit edilmiştir. Mayısın ilk haftasından itibaren görülmeye başlanan Elma içkurdu tuzaklarda eylül ayı sonlarına kadar görülmeye devam etmiştir. Beyşehir'de Elma içkurdu yaklaşık 4.5 ay süre ile doğada aktif olarak bulunmaktadır.

Hava sıcaklıklarının artmasıyla popülasyon en üst noktasına temmuz-ağustos aylarında ulaşmaktadır. Bu aylarda yükselen popülasyon nedeniyle sezon sonuna doğru meyvelerdeki bulaşıklık oranında da artış gözlenmiştir. Çalışmanın ilk yılında Genek' de haftalık kontrollerde ilk başlarda \%4-5 oranında olan bulaşıkııık, ağustos sonundan itibaren \%26-27 seviyesine çıkmıştır. Çalışmanın ikinci yılında bulaşıklııı oranı son dönemlerde \%4-7 arasında değişmiştir. Diğer bahçelerde her iki yılda da bulaşıklılığın \%1 seviyesinde olduğu belirlenmiştir. Ayrıca bulaşıklılı̆ın bahçeleri çevreleyen elma ağaçlarındaki meyvelerde daha yüksek olduğu gözlemlenmiştir.

Beyşehir'de yapılan bu çalışma ile Elma içkurdu mücadelesinde popülasyon takibinin ne derece önemli olduğu ortaya konulmuştur. Popülasyon takibi sayesinde elma bahçelerinde yapılması muhtemel fazla kimyasal kullanımının önüne geçilebilmektedir. Elma içkurdu popülasyonunun yoğun olduğu dönemler içerisinde etki süresi uzun ilaçlarla yapılacak 3-4 ilaçlama ile mücadelede sonuç alınabilir. Bu sayede fazla ilaç kullanımının hem ekonomik hem de çevre ve insan sağlığı açısından olumsuz etkilerinden korunmak mümkündür. Ülkemizde yapılan çalışmalarda üreticilerin Elma içkurdu ile mücadelede yıl içerisinde 8-12 kez kimyasal mücadele yaptıkları belirtilmektedir (Şahin, 2010).

Çalışmanın ilk yılında üreticinin kendi belirlediği tarihlerde ilaçlama yaptığı Genek'de bir yıl sonra popülasyon gelişimi dikkate alınarak 15 Mayıs, 5 Haziran, 4 Temmuz ve 11 Ağustos tarihlerinde yapılması sağlanan 4 ilaçlama ile bir önceki yıl \%14.4 olan bulaşıklığın 2015 yılında \%3.1 seviyesine kadar düştüğü görülmüştür. Çiftçilerin resmi kurumların Elma içkurdu ilaçlama uyarılarını dikkate aldıkları takdirde mücadelede başarı oranları artacaktır.

Eğirdir'de (Isparta) erkenci elma çeşitlerinin zararlının sadece birinci dölünden etkilendiğini, orta mevsim ve geç̧̧ elma çeşitlerinin hasat zamanının gecikmesi nedeniyle zararlının ikinci dölünden de etkilenmesi nedeniyle daha fazla zarar gördüğü bildirilmiştir (İşci, 2008). Çoğu bölgede olduğu gibi Beyşehir'de de erkenci çeşitlerin ve zarar görme oranı düşük olduğu belirlenen çeşitlerin tercih edilmesi bahçe tesisi açısından önemlidir.

Geleneksel şekilde yapılan yetiştiricilikte yaşlanmış ağaç kabukları arasında pupa olma 
imkanı ve gelişmiş taç oluşumu nedeniyle bahçelerde yapılan ilaçlamaların homojen olarak yapılamaması nedeniyle popülasyon yoğunluğunda artışa sebep olduğu görülmektedir. Bu nedenle mümkün olduğu ölçüde yeni tesis edilen bahçelerin daha modern ve bodur çeşitler kullanılarak kurulması önem arz etmektedir.

Geleneksel yetiştiricilik yapılan bahçelerde ise ağaç gövdelerine oluklu mukavva sarılarak buralarda oluşan pupaları imha etmek ve yere düşen bulaşık meyvelerin bahçeden uzaklaştırılması gibi kültürel önlemlere uyulması mücadelede de başarı imkânını artıracaktır. Ayrıca birbirine bitişik şekilde gelişen meyvelerin seyreltme yoluyla alınması ilaçlamalarda bütün meyve yüzeyinin ilaçla kaplanmasını sağlaması nedeniyle gerekli bir uygulamadır.

İtalya'nın Molise bölgesinde Elma içkurdunun konukçu bitki şeritleri ile çevrilmiş elma bahçelerindeki hareketliliğinin azaldığı belirtilmiştir. Elma bahçeleri etrafında yapılacak en az 100 m genişliğindeki bitki şeritlerinin bulaşık bölgelerden gelen göçlere karşı bariyer etkisi olduğu belirtilmektedir (Trematerra ve ark., 2004). Yeni kurulacak elma bahçelerinin çevresine imkânlar ölçüsünde dayanıklı elma çeşitlerinin şerit bitki olarak kullanımının sağlanmasının $C$. pomonella popülasyonunun kontrolünde önemli katkılar sağlayacağı düşünülmektedir.

\section{Ekler}

Bu çalışmada kullanılan veriler, Hasan ÇELIK'in yüksek lisans tezinden alınmıştır. Çalışma Uluslararası Katılımlı 6. Bitki Koruma kongresinde poster olarak sunulmuştur.

\section{Kaynaklar}

Yöntemlerinin Insektisitlerle Kombine Uygulanması Üzerine Bir Araştırma, Türkiye IV. Bitki Koruma Kongresi Bildirileri, 33.
Ahmad, K. F., Shah, W. H., Jilali, S., 2003. Phenology of codling moth, Cydia pomonella L. (Tortricidae:Lepidoptera) on apple trees in Kashmir-Pakistan, Sarhad Journal of Agriculture, 19 (12): 239-243.

Anonim, 2008. Zirai Mücadele Teknik Talimatları, Cilt 4, Ankara, Tarım ve Köyişleri Bakanlığı Tarımsal Araştırmalar Genel Müdürlüğü, 145-158.

Anonim, 2011. Elma Entegre Mücadele Teknik Talimatı, Ankara, Gıda, Tarım ve Hayvancılık Bakanlığı Tarımsal Araştırmalar ve Politikalar Genel Müdürlüğü, 21-32.

Anonim,

2015a. https://tuikapp.tuik.gov.tr/bitkiselapp/bitk iselzul, [11.11.2015].

Bayraktar, S., 2015. Karaman ilinde Elma Bahçelerinde Elma İçkurdu ile Kimyasal Mücadelede Mücadele Zamanının Belirlenmesine Yönelik Çalışmalar, Namık Kemal Üniversitesi Fen Bilimleri Enstitüsü Yüksek Lisans Tezi, Tekirdağ, https://tez.yok.gov.tr/[11.11.2015]

Dindar, İ. ve. Ecevit, O., 1996. Cydia pomonella (L.) (Lepidoptera: Tortricidae)'nin Cevizdeki Biyolojisi ve Zararı Üzerine Araştırmalar, Türkiye III. Entomoloji Kongresi, 692-699.

Hepdurgun, B., Zümeroğlu, A. Göker, S. Hıncal, P. Yaşarakıncı, N., 1996. Ege Bölgesi'nde Elma İçkurdu (Cydia Pomonella (L.))'na Karşı Kitlesel Tuzaklama Yöntemi ile Mücadele Olanaklarının Araştırılması, 1996 Zirai Mücadele Araştırma Yıllığı, 53-54.

Howell, J., Knight, A., Unruh, T., Brown, D., Krysan, J., Sell, C., Kirsch, P., 1992. Control of codling moth in apple and pear with sex pheromone-mediated mating disruption, $J$. Econ. Entomol,: 85 (3): 918-925.

İşci, M., 2008. Elma içkurdu [Cydia pomonella (L.) Lep.: Tortricidae]'nun farklı elma çeşitlerindeki zarar oranlarının belirlenmesi, Selçuk Üniversitesi Fen Bilimleri Enstitüsü, http://acikerisim.selcuk.edu.tr:8080/xmlui /handle/123456789

İşçi M., Kaymak, S., Şenyurt H., Öztürk, Y., Atasay, A., Pekteş, M., Özongun, Ş, 2011. Eğirdir (Isparta) Koşullarında [Cydia pomonella (L.) (Lepidoptera: Torticidae)] Mücadelesinde Çiftleşmeyi Engelleme

Kakar, A., Anwar, M., Kamran, K., Iqbal, F., 2015. Chemical Control of Codling Moth, Cydia pomonella L. (Lepidoptera: Tortricidae) in 
Relation to Pheromone Trap Catches and Degree Days in Upland Balochistan, Pakistan Journal of Zoology, 47 (2).

Kılıç, M., Avcl, Ü., Kahveci, Y., Erdem, B., 1999. Karadeniz Bölgesi'nde Elma iç kurdu [Cydia pomonella $\quad$ L.) (Lep.: Tortricidae)] mücadelesinde çiftleşmeyi engelleme yönteminin uygulanma olanakları üzerinde araştırmalar, Bitki Koruma Bülteni, 39 (3132): 45-55.

Knight, A. L., 2010. Increased catch of female codling moth (Lepidoptera: Tortricidae) in kairomone-baited clear delta traps, Environmental Entomology, 39 (2): 583590.

Kutinkova, H., Dzhuvinov, V., Kostadinov, R., Arnaudov, V., Terziev, I., Platon, I., RosuMares, S., 2009. Control of codling moth by "attract and kill" formulation in Bulgaria, Sodininkystè ir Daržininkystè,: 28 (4): 1926.

Layık, F. Ö., Kısmalı, Ş., 1994. Zararlılara karşı biyoteknik yöntemlerle savaşta kitle halinde tuzakla yakalama (mass-trapping) yönteminin kullanılması, Turkish Journal of Entomology, 18 (4).

Mamay, M., Yanık, E., 2013. Şanlıurfa'da Elma Bahçelerinde Elma İçkurdu [Cydia pomonella (L.) (Lepidoptera: Tortricidae)]'nun Populasyon Gelişimi ve Farklı Metotlar Kullanılarak Bulaşıklık
Oranının Belirlenmesi, Tarım Bilimleri Dergisi, 19 (2): 113-120.

Oğuz, C., Karaçayır, H. F., 2009. Türkiye'de Elma Üretimi, Tüketimi, Pazar Yapısı ve Dış Ticareti, Tarım Bilimleri Araştırma Dergisi, 2 (1): 41-49.

Önder, P. E., 1987. Ege Bölgesi'nde Elma içkurduna karşı ilaçlı savaşımda tahmin ve uyarıya esas olarak eşeysel çekici tuzaklarla, etkili sıcaklık toplamlarından yararlanma olanakları, Türkiye I. Entomoloji Kongresi, 15-24s.

Özpınar, A., Şahin, A. K., Polat, B., 2009. Çanakkale İlinde Elma içkurdu [Cydia pomonella (L.) (Lepidoptera: Tortricidae)]'nun yayılış alanı ve popülasyon gelişmesinin belirlenmesi, Türkiye III. Bitki Koruma Kongresi, 100s.

Şahin, A. K., 2010. Çanakkale İlinde Elma İçkurdu [Cydia pomonella (L.) (Lepidoptera: Tortricidae)]'nun Popülasyon Gelişmesinin ve Bazı Biyolojik Özelliklerinin Belirlenmesi. Yüksek Lisans Tezi Çanakkale On Sekiz Mart Üniversitesi Fen Bilimleri Enstitüsü, Çanakkale, https://tez.yok.gov.tr/[11.11.2015].

Trematerra, P., Gentile, P., Sciarretta, A., 2004. Spatial analysis of pheromone trap catches of codling moth (Cydia pomonella) in two heterogeneous agro-ecosystems, using geostatistical techniques, Phytoparasitica, 32 (4): 325-341. 